\title{
Development of semi-synthetic diet for laboratory rearing of western corn borer (Ostrinia spp.) in Kobe, Japan
}

\author{
S Pokhrel ${ }^{1}$ and S Wijarn ${ }^{2}$ \\ ${ }^{1}$ Crop Development Directorate, Lalitpur, Nepal \\ ${ }^{2}$ Chyaiyaphum Agriculture Collage, Thailand
}

\begin{abstract}
A pair wise experiment was conducted, aiming to develop an artificial diet for laboratory rearing of Ostrinia species and for understanding their developmental characteristics in the control environment in insect physiology lab, Kobe University, Japan. Eleven different diets with various recipes were tested to observe the performance of diets and to evaluate the developmental characteristics of three Ostrinia species. In general, the survival was highest with $O$ zaguliaevi adapted nearly all diets we prepared, $O$ furnacalis survived fairy well but none of the diet was found satisfactory for rearing $O$ scapulalis. The period of larval stage was shortest in $O$ zaguliaevi, longest in $O$ furnacalis and intermediate in $O$ scapulalis. Photoperiodism was observed with both $O$ scapulalis and $O$ furnacalis. The type of photoperiodoic response was a typical long day type. Different diet resulted in one hour difference in the critical photoperiod in case of $O$ scapulalis.
\end{abstract}

Key words: Diet, rearing, developmental characteristics, survival, photoperiodism

\section{Introduction}

The study aimed to development of artificial diets both for laboratory rearing of Ostrinia species and for understanding their developmental characteristics in the controlled environment. The importance of this study has two folds. First mass culture techniques are of vital importance to develop future biological control system of these moths since this genus contains several important pests species world wide. Secondly, the genus shows several biologically interesting problems. The taxonomic status of pheromone polymorphism in North American $O$ nubilalis is very complex (Saito. 1991). Colonization on the same host plants by closely related species for example; $O$ scapulalis and $O$ furnacalis, subsequent competition and the development of cohabitation mechanism are immensely interesting. Diapause and photoperiodic time measurement are well worked out in $O$ nubilalis which is one of the model insects for studying the regulatory mechanism of larval diapause. Although Chilo suppressalis can serve a model for larval diapause, the regulatory mechanism for diapause is different from Ostrinia. The development of artificial diet should thus merit stable supply of the experimental materials and rearing bed for biological control agents.

\section{Methodology}

\section{Insect collection}

The egg masses laid by field collected $O$ scapulalis and $O$ furnacalis were sent from Dr. Yutaka Yoshiyasu of Kyoto Prefectural University (Kyoto). The adults were caught in the field in Kyoto. Twenty-nine egg masses of $O$ zaguliaevi were sent by Mr. Shigeyuki Iimura of Iwate Agricultural Experiment Station (Morioka). The egg masses were kept in the Mason jar with a sheet of wet blotting paper at the bottom. Newly hatched larvae crawled up the wall since they have a positive photo taxis. Individuals were picked up by a small brush and inoculated on the diet which was placed in the designed environmental conditions. 


\section{Diet preparation and recipes}

Totally 11 kinds of diets were prepared (Table 1) and one commercially available diet (INSECTA LF) was also used.

The basic ingredient for this model artificial diet was one out of Green beans (g), Kidney beans ( $\mathrm{g}$ ), Azuki beans (g), Pop corn (g), Millet (ground) (g), Fresh corn (g) and Mouse Diet (g) which stimulates the larva of $O$ species on feeding the diet. Since, the basic host of $O$ furnacalis is graminaceae, we prepared some diets using fresh corn. For the same reason we prepared other diets using millets that was using for pet bird feeds which was available all year round. These ingredients supplies carbohydrates $(\mathrm{CHO})$ or protein. Wheat bran as a $\mathrm{CHO}$ supplement and yeast as protein supplement were mixed in all 11 diets. Vitamins example; Ascorbic acid, Cystein Hcl, Methyl - P- Benzoic acid were used as essential elements of the model diet. Formalin was used as disinfectant; Agar to solidify the diet, tochopheral as an anti oxidant, sorbic acid to prevent the fungal growth on diet, corn oil as a micro element to supply fat, and sitistcrol as additional feeding stimulant were also mixed in the diets in different concentration (Table 1). All ingredients were mixed with melted agar and blended in a win blender thoroughly and poured into sterilized polystyrene containers. Then the diet was solidified in the refrigerator. The surface of diet was cut in grid to facilitate the larvae to tunnel. Then the prepared diets were used to feed the larvae of different Ostrinia species, reared on the incubators with various combinations of photoperiods (LD 11:13, $12: 12,13: 11.14: 10,15: 9$ and 16:8) and temperatures $(17,20,25,30$ and 350C) in the constant temperature rooms. Rearing was started with one diet and subsequent modifications were made and used step by step.

Table 1: Recipes of the artificial diets prepared

\begin{tabular}{|c|c|c|c|c|c|c|c|c|c|c|c|c|}
\hline \multirow[t]{2}{*}{ Ingredients } & \multicolumn{12}{|c|}{ Diet } \\
\hline & 1 & 2 & 3 & 4 & 5 & 6 & 7 & 8 & 9 & 10 & 11 & $12 *$ \\
\hline Green beans (gms) & 50 & 50 & & & & & & & & & & \\
\hline Kidney beans (gms) & & & 50 & 50 & & & & & & & & \\
\hline Azuki beans (gms) & & & & & & & 50 & 50 & & & & \\
\hline Pop corn (gms) & & & & & & & & & 50 & 50 & & \\
\hline Millet (ground) (gms) & & & & & & & & & & & 25 & \\
\hline Fresh corn (gms) & & & & & 50 & 50 & & & & & & \\
\hline Mouse Diet (gms) & & & 10 & 10 & & 10 & & & & 10 & 25 & \\
\hline Wheat bran (gms) & 50 & 50 & 40 & 40 & 40 & 40 & 50 & 40 & 40 & 50 & 25 & \\
\hline Yeast (gms) & 20 & 20 & 20 & 20 & 20 & 20 & 20 & 20 & 20 & 20 & 10 & \\
\hline Casein (gms) & & & 10 & 10 & 10 & 10 & 10 & 10 & 10 & 10 & 5 & \\
\hline Sucrose/Honey (gms) & & 2.5 & 2.5 & 2.5 & 2.5 & 2.5 & & 2.5 & 2.5 & 2.5 & 5 & \\
\hline Cystein/ Chlorela (ml) & 0.2 & 0.2 & & & & & 0.2 & & & & 10 & \\
\hline Corn oil (ml) & & & 1 & 1 & 1 & 1 & 1 & 1 & 1 & 1 & 1.5 & \\
\hline Sitosterol/Cholesterol (ml) & & 1.5 & 1 & 1 & 1 & 1 & 1 & 1 & 1 & 1 & & \\
\hline Ascorbic acid (ml) & 2 & 2 & 2.5 & 2.5 & 2.5 & 2.5 & 2 & 2.5 & 2.5 & 2 & 2.5 & \\
\hline Sorbic acid (ml) & & 4 & 0.5 & 0.5 & 0.5 & 0.5 & & 0.5 & 0.5 & 0.5 & 0.5 & \\
\hline Propionic acid (ml) & & & 0.5 & & 0.5 & 0.5 & & 0.5 & 0.5 & 0.5 & 0.5 & \\
\hline Formalin $(\mathrm{ml})$ & 1.7 & 1.7 & 1.5 & 1.5 & & 1.5 & 1.7 & 1.5 & 3 & 3 & 1.5 & \\
\hline Methyl-p-ben (ml) & 1.4 & 1.4 & 1.5 & 1.5 & 1.5 & 1.5 & 1.4 & 1.5 & 1.5 & 1.5 & & \\
\hline Tochopherol (ml) & & 1 & 0.5 & & 0.5 & 0.5 & & 1 & 0.5 & 0.5 & 0.5 & \\
\hline Wesson's salt (gms) & & & & 2.5 & & 2.5 & & & & 2.5 & & \\
\hline Agar $(\mathrm{gms})$ & 6 & 16 & 5 & 5 & 5 & 5 & 6 & 5 & 5 & 5 & 6.5 & \\
\hline Dist. Water (ml) & 350 & 350 & 350 & 350 & 350 & 350 & 350 & 350 & 350 & 350 & 375 & \\
\hline
\end{tabular}

* INSECTA-LF 


\section{Observations on the performances of diets}

The performances of diets were judged on the following criteria:

- The rate of survival both for larval and pupal stages.

- The rate of abnormal molting,

- Pupal weight,

- Forewing length of adults, and

- The number of egg masses lay.

Since some diets developed mold, the insects were transferred a new diet. The effect of diet change was also compared with the performances of moldy diet.

\section{Observations on the developmental characteristics}

The egg hatching, pupation and adult emergence were daily examined. The incidence of diapause was calculated at the time the pupation completed in non-diapause condition.

\section{Results and discussion}

\section{Performances of the diets designed}

The developmental characteristics and growth performances on each diet (Table 1) were evaluated on the criteria described above. Since the supply of eggs was delayed due to the climatic anomaly. The overwintering generation of Ostrinia species were not available. The active population appeared very late in August. The experiment with egg masses of $O$ scapulalis, $O$ zuguliaevi and $O$ furnacalis started from the last week of August and ended in October. In general, the survival was highest with $O$ zaguliaevi of the species examined, adapted nearly all diets we prepared for them including INSECTA LF. O furnacalis survived fairy well but none of the diet was found satisfactory for rearing $O$ scapulalis. We conducted the pair wise experiment to show the effect of newly added elements, which showed clearly the addition of agents preserving the diet quality, improved both developmental rate, which accelerated the final pupal weight significantly.

\section{Developmental characteristics}

The period of larval stage was shortest in $O$ zaguliaevi, longest in $O$ furnacalis and intermediate in $O$ scapulalis. Photoperiodism was observed with both $O$ scapulalis and $O$ furnacalis. The type of photoperiodoic response was a typical long day type. That was remarkable that different diet resulted in one hour difference in the critical photoperiod which was shown in $O$ scapulalis. The availability of different diets as developmental modifyer may promise a powerful experimental tool to dissect the mechanism consisting of complex underlying responses. The egg hatching, pupation and adult emergence rate in all the species were optimum in $20-25^{\circ} \mathrm{C}$ and the diapouse recorded at 17,30 and $35^{\circ} \mathrm{C}$ ). Observation will be continued and further detail in the development in O furnacalis and $O$ zaguliaevi will appear soon. 


\section{Conclusion and recommendation}

The experiment was delayed very much due to the delayed on the availability of egg masses. However, it has established the foundation of more comprehensive experimentation to hopefully be continued in the following years. It demonstrated general adaptability of the three important Ostrinia pest species to different artificial diets and the basic developmental characteristics which have never systematically been examined before.

\section{References}

Saito. 1991. Artificial Diets for Lepidopteran. 